\title{
DESIGN AND ANALYSIS OF STEEL STRUCTURES CONSIDERING THE 3D BEHAVIOUR OF THE JOINTS
}

\author{
Luís Simões da Silva *, Sara Oliveira, Ricardo Costa and Filippo Gentili \\ ISISE, Department of Civil Engineering, University of Coimbra, Portugal \\ *(Corresponding author: E-mail: luisss@dec.uc.pt)
}

\section{A B S T R A C T}

This paper discusses the analysis and design of steel structures using 3D structural models and incorporating the 3D behaviour of the joints. Firstly, the implications of the 3D behaviour of the joints are discussed at the joint level, leading to the need to develop 3D component models. Subsequently, at the frame level, a 3D joint macro-element is presented that encapsulates the behaviour of the joints at each node while maintaining compatibility with the global degrees of freedom of beam elements. Finally, an example is shown for a simple 3D framed structure.

\section{A R T I C L E H I S T O R Y}

$\begin{array}{ll}\text { Received: } & 18 \text { March } 2020 \\ \text { Revised: } & 18 \text { March } 2020 \\ \text { Accepted: } & 18 \text { March } 2020\end{array}$

Accepted: $\quad 18$ March 2020

\section{K E Y W O R D S}

Steel

Stability;

3D joints;

Eurocode 3;

Macro-elements;

OpenSees

\section{Introduction}

Most structures are tri-dimensional, i.e. develop along three directions, because of their basic function of providing a protected enclosure for people and goods. Many structural schemes and materials exist to address the challenge of choosing the best option for a given building meet this requirement with proper safety levels. Among these, it is the art of the designer to select and optimise the options that maximise sustainability.

The choice of structural schemes is naturally linked to the characteristics of the various structural materials and products (e.g. the large difference between the tensile and compressive resistances of concrete or the susceptibility of steel members to instability phenomena), but it is also intrinsically linked to the knowledge and calculation capabilities that are available throughout the design process and the availability of construction technologies that allow to materialise the design concepts.

Steel structures provide competitive structural solutions, particularly in combination with other materials such as concrete and timber. Multi-storey buildings are often supported by a steel or a steel-concrete composite framed structure, a concrete core and concrete or composite floor systems. Low-rise single storey buildings covering medium to large spans are often supported by steel framed structures and lightweight roofs made from steel panels. In these both cases, steel columns are connected to steel beams that intersect the columns at the various floor levels with an orthogonal grid in the case of regular structures but not necessarily so in an irregularly shaped building. Iconic examples of a highly irregular grids and structures are the Guggenheim Museum in Bilbao or the Beijing National Stadium in Beijing.

Historically, because of limited calculation resources, framed structures were calculated and designed as a set of $2 \mathrm{D}$ frames. The theoretical background of this procedure relied in the assumption that the behaviour of this type of structures was not significantly affected by torsional effects and, consequently, their structural response could be adequately represented by independent orthogonal frames. Pitched-roof portal framed buildings are typical examples of a structure that can be modelled and calculated as independent structures in two perpendicular directions.

Nowadays, the available computational resources have eliminated those limitations. Hence, today's standard practice corresponds to the development of $3 \mathrm{D}$ framed models of the structure that, besides representing its behaviour with much higher accuracy, present the added advantage of speeding up the design process, given the user-friendliness of most structural analysis and design software packages.

The consideration of 3D structural models of framed structures requires that the stiffness of the various beam-to-column joints is appropriately modelled. Fig. 1 illustrates beam-to-column joints resulting from the intersection of four orthogonal beams, common in 3D framed structures.

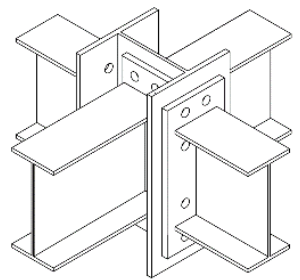

a) I-shaped column

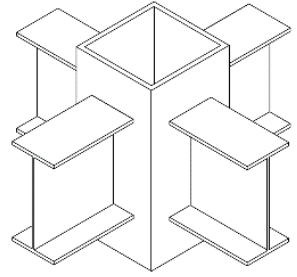

b) tubular column
Fig. 1 Detail of beam-to-column joints where 4 beams intersect the column.

Fig. 1a represents two usual joint typologies: end-plate major-axis joints, whereby the beam connects to the flange of the column and end-plate minoraxis joints, whereby the beam connects to the web of the column. End-plate major axis joints are usually moment-resistant joints, either full-strength or partial-strength. In contrast, end-plate minor axis joints directly connected to the column web are either nominally pinned or partial-strength. Although the four joints comprise several components that are independent [1], they all share some common components (in particular the column web panel components) that need to be designed considering the $3 \mathrm{D}$ interactions that may control their behaviour.

Fig. $2 b$ represents a typical joint typology to connect I-section beams to a SHS column. In this case, because of symmetry, the 4 joint typologies are similar and correspond to end-plate beam-to-column joints. Because of the slenderness of the column faces, it is well known that the local behaviour of the column depends on the stiffness of each individual beam-to-column joint and it may be assessed using a modified ring model [2, 3]

Obviously, more complex joint details may be adopted that allow to disregard the $3 \mathrm{D}$ interactions in the nodal zones of a column or even allow to neglect the flexibility of the joints by considering fully rigid and fully pinned joints as it is illustrated in Fig. 2 [3, 4]. However, these solutions usually lead to increased cost.

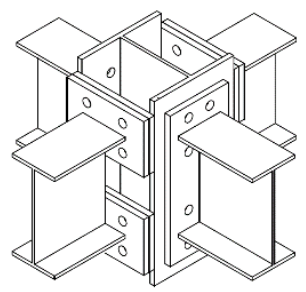

a) I-shaped column

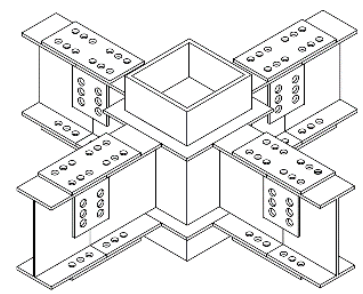

b) tubular column
Fig. 2 Detail of complex beam-to-column joint where 4 beams intersect the column. 
Hence, as the trend to optimization having in view the increase of the competitivity of steel structures seems irreversible, even from a resourceefficiency point of view [5], it is necessary to capture the 3D interactions that occur at each column node and to consider their implications for the global analysis of the structure as well as the local design of each joint [6].

This paper presents a framework and a design-oriented methodology for the analysis and design of steel structures incorporating the 3D behaviour of the joints. It addresses the local level, i.e. joint level, and the global level, i.e. frame level, followed by the presentation of the development and application example of a 3D joint macro-element suitable for rigorous analysis and design of 3D framed structures implemented in OpenSees [7].

\section{Joint level}

\subsection{Introduction}

The behaviour of a steel joint is complex. Its characterization may therefore be addressed with different levels of sophistication. The most common ways to characterize the behaviour of steel joints are:

- Experimental tests, that constitute the most accurate procedure but require specialized human resources and equipment, a high cost and long timespan. Experimental tests are obviously essential whenever new or unproven joint configurations are developed, either to help to identify the relevant failure modes and/or to provide validation of the design procedures. Additionally, in design, experimental tests may be required in other cases, e.g. (i) whenever there is not sufficient consolidated knowledge for the application of some designs options such as, for instance, the use of dissipative steel joints in seismic conditions [8] or (ii) in case of an infrastructure of high importance, whereby any structural problem might lead to expensive consequences and important delays to the use of that infrastructure, as for example, the joints in the large scale cryostat for the DUNE experiment [9].

- Advanced finite element models, that constitute the most accurate and versatile theoretical procedure but require model calibration, qualified and experienced users and are time consuming. Numerical finite element models are nowadays extensively used to (i) enlarge the range of validity of design solutions through parametric studies, (ii) validate design assumptions and (iii) get detailed insight into local behaviours in complex cases that lack simpler design guidance.

- Mechanical models, that provide an accurate representation of the moment-rotation behaviour of the joint typologies that are covered by their application field and are easily incorporated in design codes but, because they require the calibration of the behaviour of the components and the adequacy of the underlying component model, are not available for all joint typologies that may be used in practice.

This third option is of course favoured for practical application because it is the only option that is compatible with the design deadlines and design fees that cover $90 \%$ of the cases. This approach will be further detailed in the following section, although it is worth mentioning that some hybrid FEM mechanical model approaches are starting to appear in the engineering community.

\subsection{Component method approach}

The component method is the usual designation of a methodology for the assessment of the behaviour of steel joints based on simplified mechanical models. In order to achieve a user-efficient solution, the component method identifies the stress paths that are generated in a joint subject to a given loading. After that, the portions of the joints that have a contribution for the joint behaviour are identified, characterized and condensed in tensile or compressive stress resultants.

The joint is represented by a discrete rigid link-spring model, whereby each spring represents the behaviour of a physical part of the joint subject to a specific loading, henceforth called joint component. It is further noted that the component model may be used with various levels of sophistication, depending on what is desired: whenever only the initial stiffness of the joint is of interest, it is only required to define the behaviour of each component by their linear elastic stiffness. Similarly, if only the resistance of the joint is of interest, it is only necessary to define the resistance of each component. Finally, to obtain the full moment-rotation response of the joint, it is necessary to define the nonlinear force-deformation behaviour of each component that may be represented in a simplified way by bilinear curves.

Although most of the mechanical models developed in the scope of the component method correspond to statically indeterminate structures, simplified generic solutions were developed for the initial stiffness and the resistance that were implemented in design codes [10], providing a practical and speedy way to assess the properties of a joint. Furthermore, most structural design software packages already provide modules to assess the properties of steel joints making use of the component method [11-14].

As becomes clear from the above, the component method relies on the mechanical characterization of the components. Much research effort was dedicated to the development of design models of the key components of a steel joint. Nowadays, a reasonable number of components covering a wide range of joint typologies are well characterized and design expressions/models for their mechanical properties are available in design codes. Fig. 3 illustrates several beam-to-column joint mechanical models developed in the scope of the component philosophy that are appropriate for specific joint typologies.
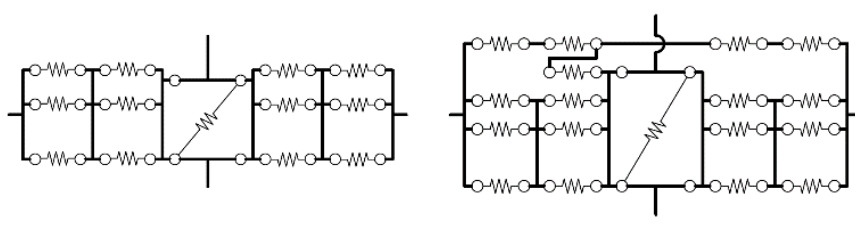

a) internal node (steel joints) [15]

b) internal node (composite joints) [16]
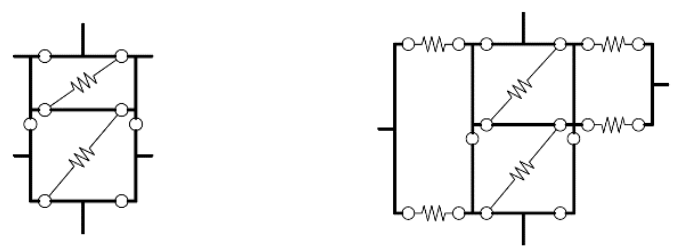

c) Internal node (composite joints) [17]

d) internal node (steel joints, beams of unequal depth) [18]

Fig. 3 Component method mechanical models for beam-to-column major axis joints.

However, design creativity combined with powerful advances in manufacturing and processing technologies (e.g. 3D printing, just to mention a disruptive technology) are continuously pushing to expand the frontiers of knowledge. The need to consider the 3D behaviour of the joints is one of the consequences.

At present, the component method was basically developed to address uniplanar joints (covering both external and internal nodes), see Fig. 3. Concerning 3D component models, apart from the work developed at the University of Coimbra [19], little work exists in this field. The difficulty starts with the lack of experimental evidence to characterize the components that are relevant for $3 \mathrm{D}$ behaviour and the crucial issue of the interactions that need to be considered. This issue will be tackled in section 2.4.

\subsection{Detailed FEM approach}

Among designers there is a growing wish of addressing the design of the joints by means of advanced nonlinear structural models that detail the nodal zones using shell and solid finite elements. This is of course the desirable future but it is not realistic at the present moment because, besides all the other reasons already mentioned above, (i) the required computing processing resources are not available for a normal design company and (ii) there are not available yet clear and objective numerical "failure" criterion that allows to establish a "component resistance". Besides all the complex phenomena that are present in a steel joint (complex geometry, contact and separation, plasticity and strain hardening, local instabilities, large local deformations, etc.), it is also necessary to adequately interpret peak strains that may occur and that are purely numerical effects that do not correspond to reality but may mask the true results.

Hence, a more realistic approach is to try to interpret and condense the detailed local FEM results (stresses and deformations) into equivalent joint components that follow the principles of the component method. Augusto et al. $[20,21]$ have developed a methodology to extract the component behaviour from advanced nonlinear numerical models for the column web panel components, both under static monotonic conditions and cyclic conditions. Fig. 4 illustrates the extraction methodology for the component's column web in transverse tension and compression (Fig. 4a and Eq. (1)) and the component column web panel in shear (Fig. 4b and Eq. (2)).

$$
F_{c}=\left(\int^{h_{c}} \sigma_{33} d y\right) \cdot t_{w c}, \quad F_{t, i}=\left(\int^{h_{t, i}} \sigma_{33} d y\right) \cdot t_{w c}
$$




$$
\begin{gathered}
V_{n}=\left(\int^{\left(2 t_{f c} / 3+r\right)_{b a c k}} \tau_{23} d z\right) \cdot t_{1}+\left(\int^{h_{w c}} \tau_{23} d z\right) \cdot t_{w c}+ \\
\left(\int^{\left(2 t_{f c} / 3+r\right)_{f r o n t}} \tau_{23} d z\right) \cdot t_{1}
\end{gathered}
$$

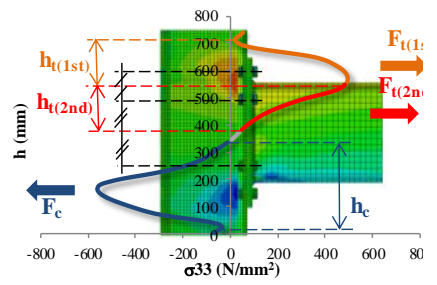

a) Computation of normal force of the column web in transverse tension and compression components.

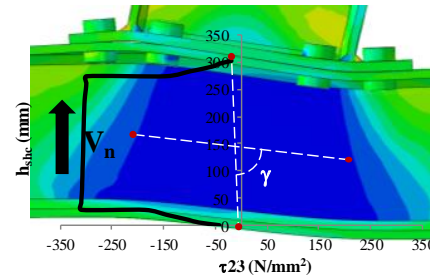

b) Computation of the shear force of the column web panel in shear component.

Fig. 4 Computation of internal forces in components from detailed FEM models [20].

\section{4. $3 D$ component characterization}

Focussing on an internal node of a I-shaped column as shown in Fig. 1a, it is clear that the key 3D effects and interactions are concentrated in the column web panel. In order to assess and understand the underlying 3D behaviour of the joints converging to a 3D node, five full scale experimental tests over 5 distinct specimens were carried out at the University of Coimbra [22, 23]. The tested specimens are sub-frames from a representative unbraced regular frame acted by horizontal loads extracted between points of contra-flexure - bolted extended end-plate joints were considered in both minor and major axis directions. Fig. 5 shows the schematic layouts of the five beam-to-column joints tested.
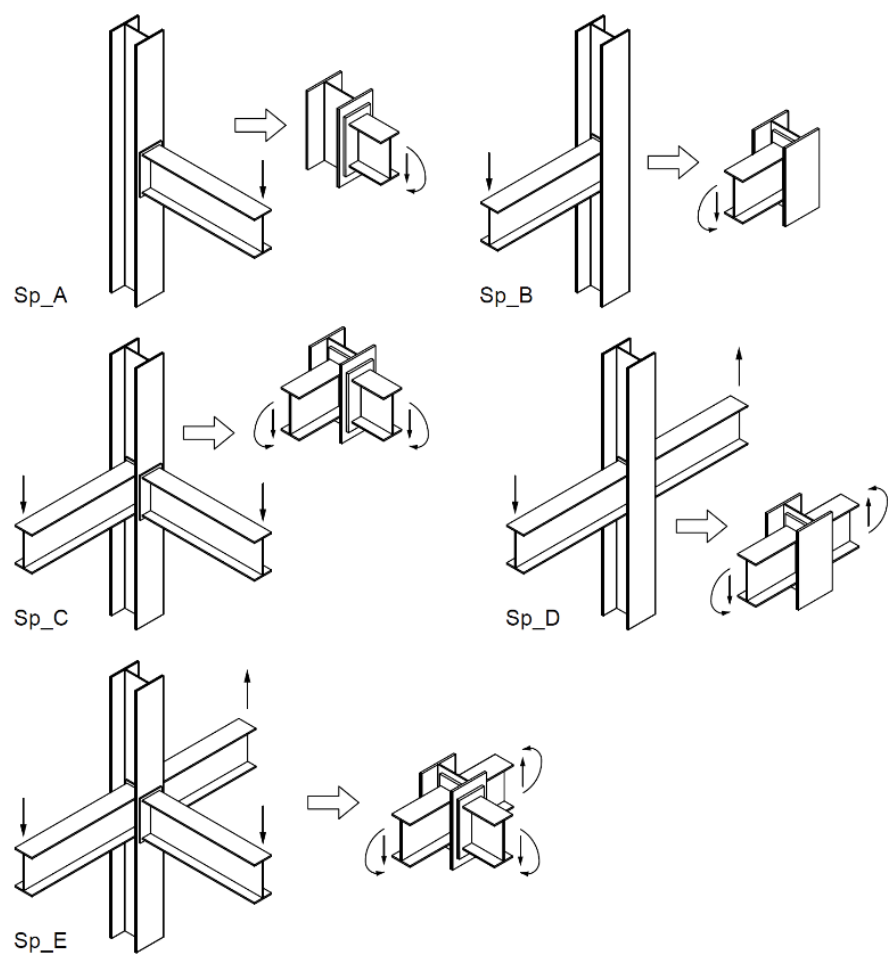

Fig. 5 Schematic representation of the experimental tests.

Fig. 6 shows the behaviour of the major axis joints and the minor axis joints [24]. It was found that, for the column web slenderness tested, the minor axis joint may lead to a reduction of the major axis joint initial stiffness due to the interaction of the minor axis joints with the load introduction components (in plane) of the major axis joint, i.e. the column web in tension (CWT) and the column web in compression (CWC).

It was also found that the post-elastic stiffness of the column web in shear (CWS) is enhanced due to the interaction with the minor axis joints and the enhancement is larger in beam-to-column joints with double minor axis joints than in beam-to-column joints with a single minor axis joint. No major differences in the plastic moment of major axis joints were found due to the interaction with the minor axis joints [24].
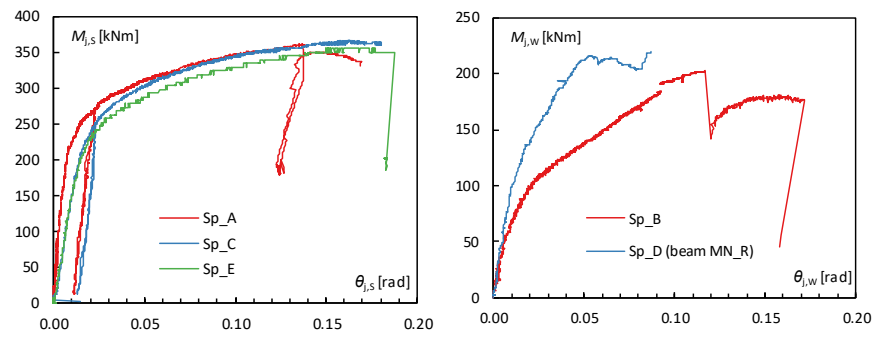

Fig. 6 Behaviour of major axis joints (left) and minor axis joints (right) [24].

Additionally, it was also found that the behaviour of minor axis joints in beam-to-column joints with double minor axis joints has a major enhancement in terms of initial stiffness, post-elastic stiffness and plastic moment when compared with the behaviour of beam-to-column joints with a single minor axis joint. Moreover, it was found that the initial stiffness of minor axis joints in beam-to-column joints with double minor axis joints is of the same order of magnitude of the initial stiffness of the major axis joints in 3D joints, showing that the pinned assumption usually considered for minor axis joint may be too conservative [24].

Having identified the key factors in the $3 \mathrm{D}$ behaviour of these joints, it is clear that a 3D beam-to-column joint model must consider the following components and interactions in the column web region of the beam-to-column joint:

- column web panel in transverse tension and compression (load introduction components in the major axis joints);

- column web panel in shear and the interaction between the major axis joints;

- column web panel in out-of-plane bending and the interaction between the minor axis joints;

- the interaction between major and minor axis joints in all these components.

\section{Frame level}

The accurate assessment of the internal forces and displacements of a 3D steel structure requires the consideration of the flexibility of the various beamto-column joints. As it was explained in the previous section, this implies that all the relevant sources of deformation of the joints are accounted for and the interactions between the relevant components from the same beam-to-column joints are appropriately considered using 3D component models. Obviously, at the frame level, this means that at each floor level all column nodes of the structural model must be detailed according to the $3 \mathrm{D}$ component model that is representative of each nodal zone.

The implementation of such an approach, although theoretically possible, is not feasible in practice for the following reasons:

- time consuming in the definition of the structural model (although this might be mitigated with a clever pre-processor);

- not robust from a calculation point of view due to the susceptibility to numerical instability associated to the large differences of the stiffness of the components and the rigid elements when compared with the stiffness of the beam elements; in case of a nonlinear analysis, this would inevitably lead to the program stopping short of the target load level;

- time-consuming at the post-processing stage.

Hence, following a previous contribution by one of the authors [25], the incorporation of the rigorous behaviour of the beam-to-column joints in the structural model (Fig. 7a) can only be achieved in a practical way with the implementation of a generalized joint element (GJ). This element should be assigned to all beam-to-column joints. However, given the actual detailing of the joints, a standard six degrees-of-freedom ( 3 translations and 3 rotations) GJ element is not sufficient. The fact that several members converge to the same region but connected to different parts of the column cross-section (flanges or web), e.g. Fig. 1a, means that the GJ element must be composed of several generalized connections (GC) and a generalized column web panel (GCWP), with appropriate eccentricities, as illustrated in Fig. 7b. 

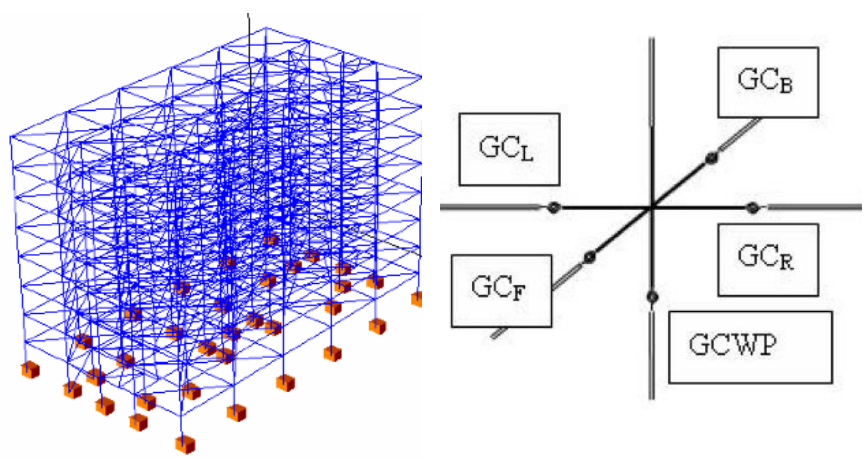

a) Structural model

b) Generalized macro-element.

Fig. 7 Conceptual definition of a generalized joint element [25]

In the next section (section 4) the development, implementation and validation of a 3D joint macro-element suitable for analysis of 3D steel frames is presented.

\section{3D joint macro element}

\subsection{Requirements for the joint macro-element}

The definition of a general beam-to-column joint macro-element, 2D or 3D, must be fully mechanically consistent with the actual behaviour of the beam-tocolumn joint. Accordingly, the arrangement of the components in the mechanical model must account for:

(i) the number of $1 \mathrm{D}$ elements (beam or column) connected to the beamto-column joint from where the demand for the components (modelled as $0 \mathrm{D}$ elements, i.e. springs) comes from;

(ii) the number of elements whose internal forces influence the constitutive relation $0 \mathrm{D}$ components.

Combining these two criteria, the following classification of components can be set:

- Type A: in these components the demand comes only from one 1D element connected to the beam-to-column joint and their constitutive behaviour can be assumed constant throughout any load history; the components in the connection (according to EC3-1-8) - except the column web load introduction components - meet these criteria because their demand comes only from one beam and their behaviour is not influenced by the internal forces transmitted to the beam-tocolumn joint by any other1D element; these components may be considered explicitly in the mechanical model but they may also be assembled in a standard 6 DOF spring;

- Type B: in these components the demand also comes only from one 1D element connected to the beam-to-column joint but their constitutive relations depends on the internal forces transmitted to the beam-to-column joint by one or more $1 \mathrm{D}$ elements, e.g. according to EC3-1-8, the strength of the column web load introduction components (CWT and CWC) is influenced by the internal forces in the columns and, according to [24] the behaviour of the CWT and CWC is also influenced by the minor axis joints; these components must be explicitly considered in the macro-element in order to be possible to account the interaction of internal forces coming from the 1D elements at any step of the load history, e.g. an increase in the column axial load due to the collapse of another column next to it may increase the CWC strength and stiffness.

- Type C: in these components the demand comes from several 1D elements connected to the beam-to-column joint and their constitutive relations depend on the internal forces transmitted to the beam-tocolumn joint by one or more $1 \mathrm{D}$ elements (just like in Type B components); the column web in shear and the out-of-plane components in minor axis beam-to-column joints meet these criteria; these components must be explicitly considered in the mechanical model in order to be possible to account the internal forces interaction and thus update the components constitutive relations throughout the load history; furthermore, their arrangement in the mechanical model must also be carefully chosen so that the internal force and the deformation of the corresponding $0 \mathrm{D}$ element are directly related to the actual internal force and deformation mode, respectively.

The 3D beam-to-column joint macro-element was developed considering this strategy and the following requirements: (i) in order to make the model fully compatible with ordinary $1 \mathrm{D}$ elements in 3D frame analysis:

a. 6 external nodes were required - in the more complex scenario four beams and two columns will be connected to the beam-to-column joint;

b. 6 degrees of freedom (DOFs) per external node were required, leading to 36 external DOFs;

(ii) in order to make the implementation of the $3 \mathrm{D}$ beam-to-column joint model in standard programs based in the Finite Element Method (FEM), all the external DOFs were made linearly independent - this required the consideration of components that, for standard deformation modes are considered irrelevant (e.g. beam major axis bending deformation in connections) but that actually can be seen a sleeping components (to which a high stiffness and strength is usually assigned) but that can also be used when nonstandard analysis with nonstandard deformation modes are required (e.g. torsion, shear deformation modes in connections, beam minor axis bending in connections, etc.); when these sleeping OD elements (the ones underlined in the following figures) are not being considered, their stiffness must be large enough to lead to almost null deformations (however small enough the avoid numerical instability issues).

(iii) to make use of the lowest number of OD element and internal DOFs to get 36 linearly independent external DOFs - in order to make the beamto-column joint as simple as possible, the lowest number of OD elements (required by the strategy already described) were used.

The need for uncouple the column web load introduction components from the rest of the connection components and the need for independent external DOFs led to OD elements placed in series. This required the consideration of internal degrees of freedom in order to be able to get kinematically defined elements, i.e. elements where any arbitrary deformation can be defined through one, and only one, appropriate choice of displacements along the nodal degrees of freedom.

The $2 \mathrm{D}$ beam-to-column macro-elements, being particular cases of the $3 \mathrm{D}$ element, may follow the same strategy and satisfy the same requirements with the obvious adaptations of only 4 external nodes and 3 DOFs per external node.

\subsection{Description of the joint macro-element}

Fig. 8 to 13 represent the DOFs of the 3D joint macro-element model and $0 D$ elements that simulate the components and the connections, where $d_{b X}$ and $d_{b Y}$ are the lever arm of the major (along X) and minor (along Y) axis beams, respectively, and $d_{c X}$ is the lever arm of the column.

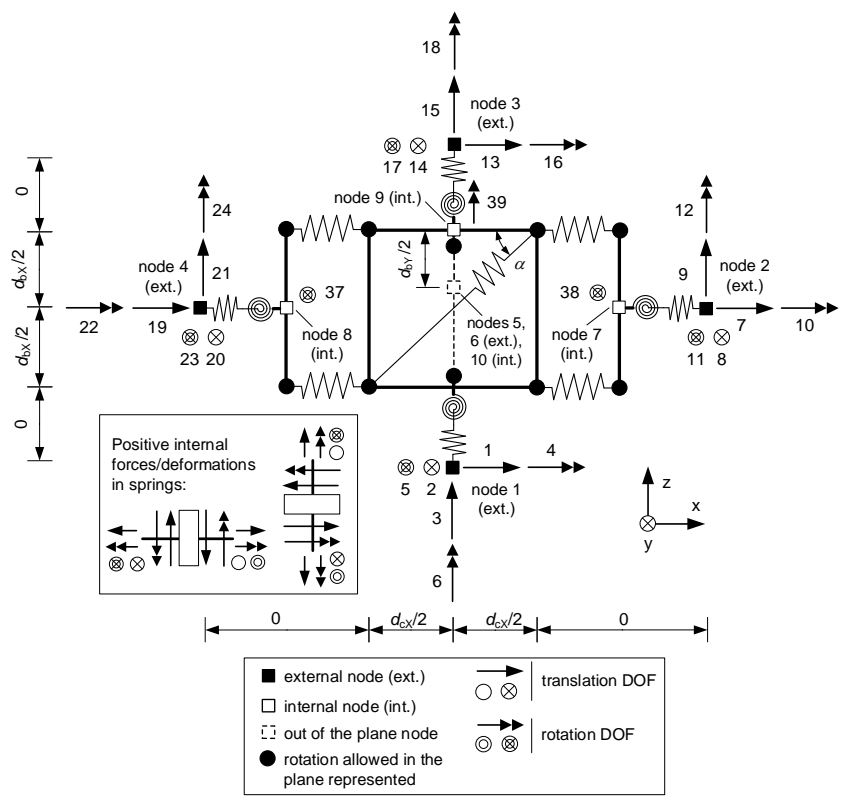

Fig. 8 Degrees of freedom and dimensions (plane XZ). 13):

The following constraints were also considered (not represented Fig. 8 to

(i) the $2 \mathrm{D}$ panels are orthogonal to each other and no relative rotation in $\mathrm{z}$ axis direction between them is allowed;

(ii) only the deformations allowed by each $0 \mathrm{D}$ element are represented where: 
- $\mathrm{T}$ stands for linear deformation; e.g. TX stands for linear deformation in the $\mathrm{X}$ axis direction;

- R stands for angular deformation; e.g. RX stands for angular deformation in the $\mathrm{X}$ axis direction.

Table 1 identifies the components/connections of the 3D joint macroelement as well as references were the mechanical behaviour of the components may be gathered from. It should also be mentioned that the 3D model incorporates the special cases of $2 \mathrm{D}$ major axis and $2 \mathrm{D}$ minor axis macroelements also developed by the authors $[26,27]$ but will be omitted for the sake of briefness.

Table 1

Summary of the $0 \mathrm{D}$ elements.

\begin{tabular}{ll}
\hline 0D element & description - reference \\
\hline 01(TX), 02(TX), 04(TX), 05(TX) & $\begin{array}{l}\text { load introduction components in the } \\
\text { column web (tension or compres- } \\
\text { sion) - major axis joints [10] }\end{array}$ \\
\hline 03(RY), 06(RY) & connections [10] \\
\hline 07(TD) & $\begin{array}{l}\text { column web in shear in plane yx - } \\
\text { major axis [10] }\end{array}$ \\
\hline 08(TZ), 10(TZ) & $\begin{array}{l}\text { column axial deformation, usually } \\
\text { sleeping components }\end{array}$ \\
\hline 09(RY), 11(RY) & $\begin{array}{l}\text { column bending deformation, usu- } \\
\text { ally sleeping components }\end{array}$ \\
\hline 12(TY), 13(RX), 14(RZ), 15(TY), & sleeping components \\
16(RX), 17(RZ), 18(RX), 19(RZ), & \\
20(RX), 21(RZ), 26(TX), 27(TZ), & \\
28(RY), 29(RZ), 30(TX), 31(TZ), & \\
& \\
\hline 22(RX), 23(RX) & 34(TY), 35(TY) \\
\hline 24(TY), 25(TY) & $\begin{array}{l}\text { connections - minor axis [10] } \\
\text { sion/compression [28, 29] }\end{array}$ \\
\hline
\end{tabular}

As stated in Table 1, spring 07(TD) in Fig. 11 represents the column web panel in shear and its behaviour can be computed according to section 6 of EN 1993-1-8 [10]. However, due to the differences in the topological configuration of the component column web panel in shear between the EN 1993-1-8 standard model and the model represented in the previous figures, an adjustment is required for the stiffness and the strength of this component. Let $S^{\mathrm{EC} 3}$ be the stiffness of column web panel in shear from EN 1993-1-8 and $S^{\mathrm{EC} 3}$ the stiffness of the spring 07(TD). For the sake of consistency, the stiffness coefficient $S^{\mathrm{EC} 3}$ in EN 1993-1-8 was derived in order to account the column web panel in shear component using the same procedures developed for the rest of the components in the connections, i.e. aligned with the bottom part of the panel. Accordingly, considering a shear deformation $\gamma$ of the column web caused by a shear force $\mathrm{V}$, the deformation of the corresponding component will be $\Delta=\gamma d_{b X}$ when the associated spring is assumed aligned with the bottom part of the panel (Case I) but will correspond to $\gamma d_{b X} \cos \alpha=\Delta \cos \alpha$ when the associated spring is assumed along the diagonal of the column web in shear (Case II). Consequently, the forces in the spring will be $S^{\mathrm{EC} 3} \Delta$ in Case I and $S^{07(T D)} \Delta \cos \alpha$ in Case II. Since the horizontal components of both springs must equal the shear force in the column web, it follows that

$$
S^{\mathrm{EC} 3} \Delta=S^{07(T D)} \Delta(\cos \alpha)(\cos \alpha) \rightarrow S^{07(T D)}=\frac{S^{\mathrm{EC} 3}}{(\cos \alpha)^{2}}
$$

Concerning the resistance $f^{\max }$ of component 7 , using the same reasoning leads to

$$
f_{7}^{\max , 07(T D)}=\frac{f^{\max , \mathrm{EC} 3}}{\cos \alpha}
$$

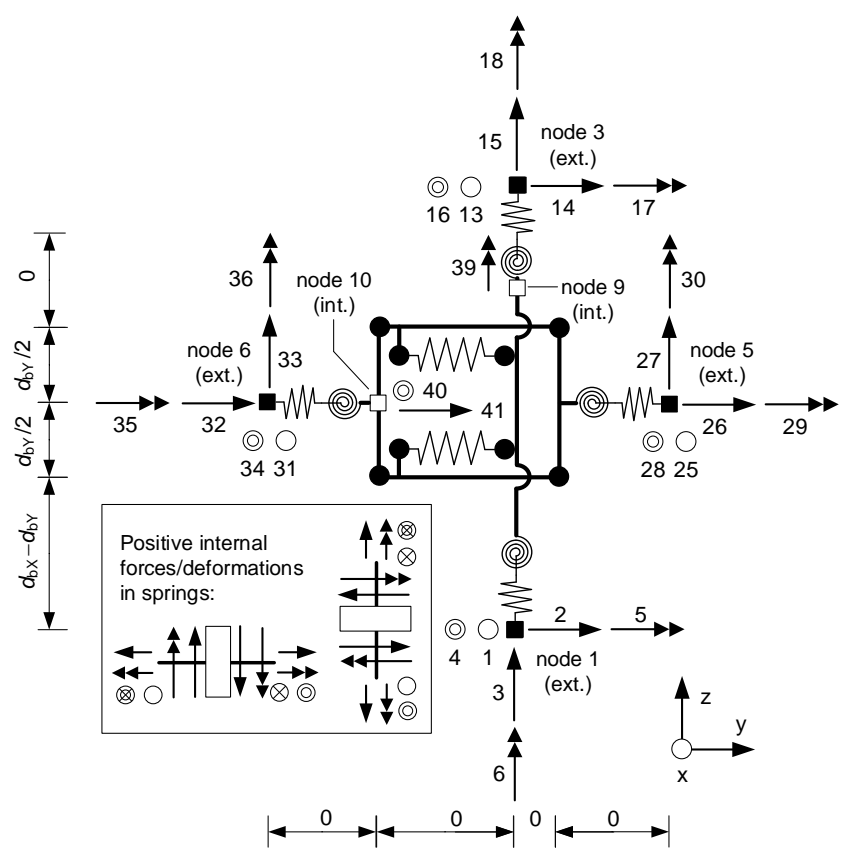

Fig. 9 Degrees of freedom and dimensions (plane YZ).

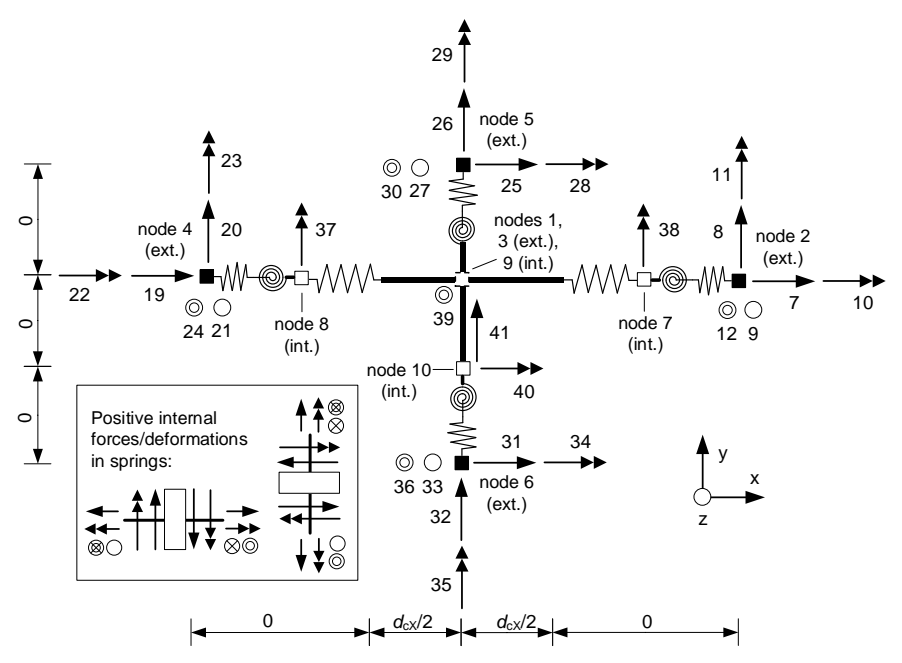

Fig. 10 Degrees of freedom and dimensions (plane YZ).

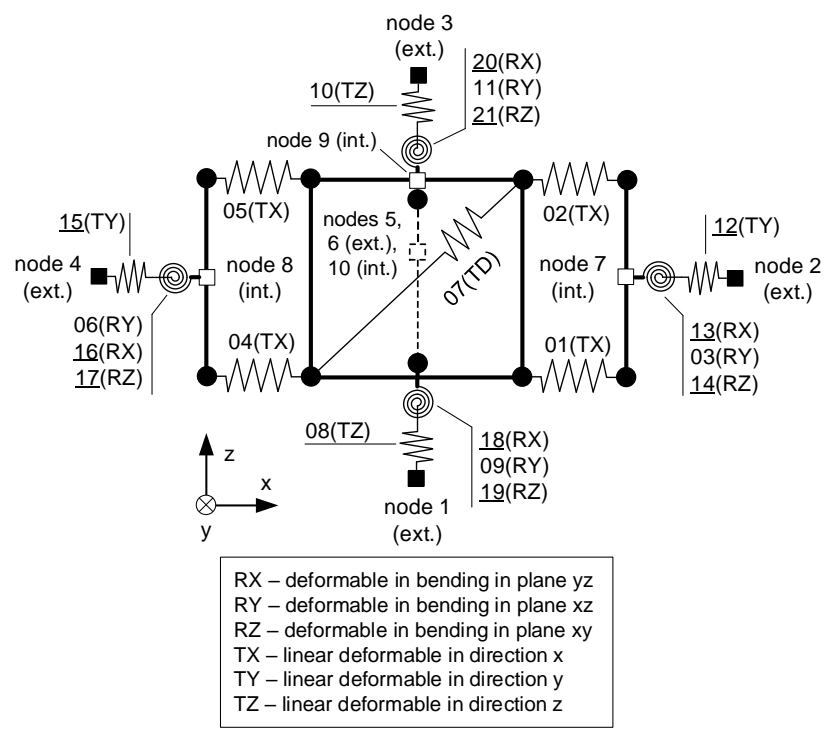

Fig. 11 Components/connections (plane XZ). 


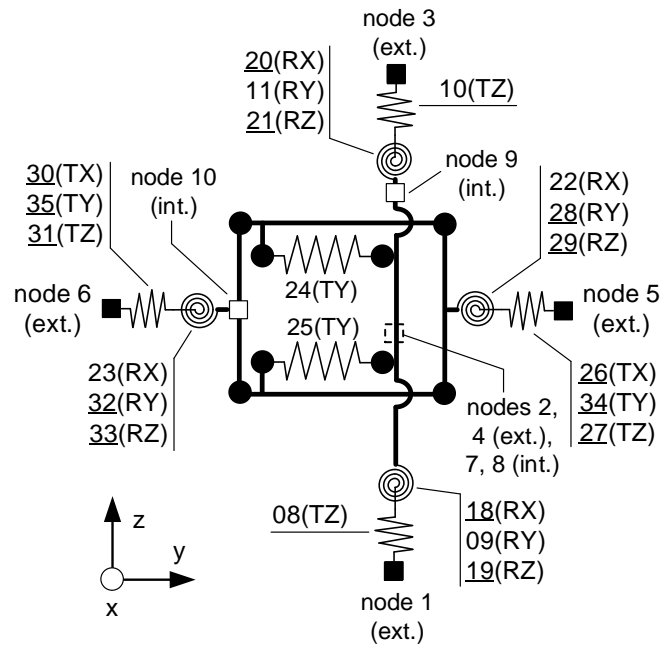

Fig. 12 Components/connections (plane YZ).

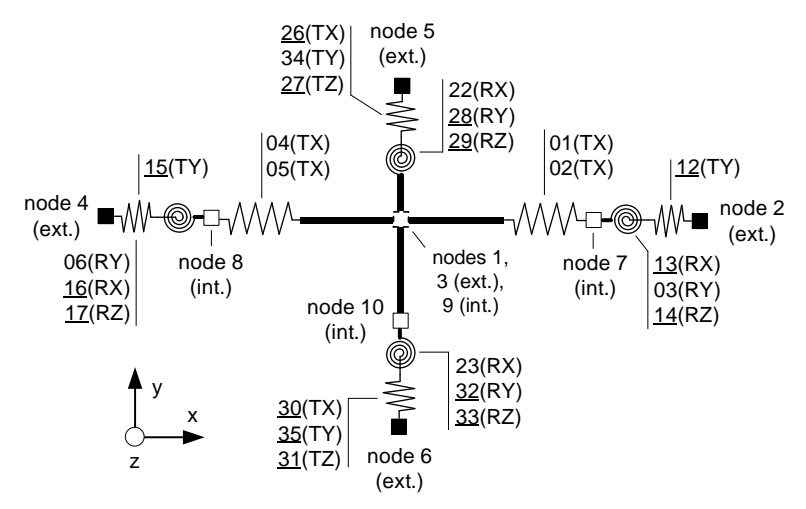

Fig. 13 Components/connections (plane XY).

In the column weak axis direction, a different strategy was considered. One of the possible strategies to account for the interaction of the bending moments coming from the beams in the weak axis directions could be a simple scissors model (see Fig. 14a) where a rotational spring allowing for rotation between the column and the beams accounts for the column web components and two additional rotational springs account for the connections. However, a more general strategy was adopted whereby two linear springs are used instead to account for the column web components (see Fig. 14b).
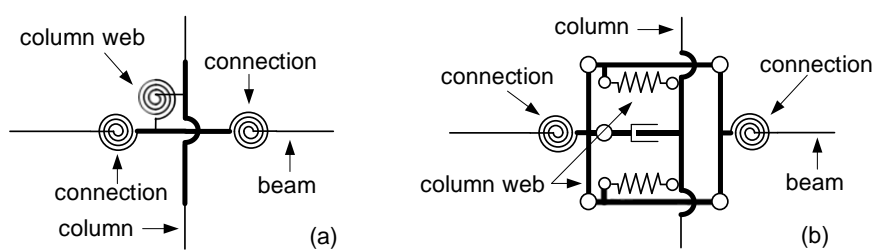

Fig. 14 Minor axis model to account for the beams interaction: (a) scissors model, (b) two springs' model.

The model represented in Fig. 14b was adopted because:

(i) it allows to account for axial forces in the beams, Fig. 15;

(ii) it allows to account for the beam "elongation/shortening" due to the different stiffness of the components;

(iii) in order to get independent external degrees of freedom in the 3D beam-to-column joint model, at least one axial component along the weak axis direction must be provided.

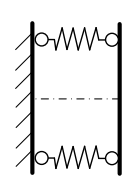

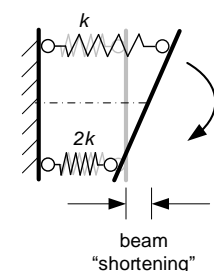

"shortening"

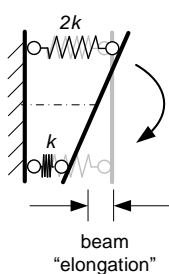

"elongation"
Fig. 15 Beams elongation/shortening due to the differences in stiffness of the transversal components in the web of the column.

\subsection{Mathematical formulation}

The linearized relation between the deformations in the springs of the model and the nodal displacements (compatibility relations) can be expressed by

$$
\Delta=A \cdot u
$$

where $A$ is the compatibility matrix, $u$ is the vector o nodal displacements and $\Delta$ is the vector of deformations in the springs. According to Fig. 8 to 13

$$
\begin{aligned}
\Delta & =\left[\begin{array}{lllll}
\Delta_{1} & \cdots & \Delta_{n} & \cdots & \Delta_{35}
\end{array}\right]^{T} \text { and } \\
u & =\left[\begin{array}{lllll}
u_{1} & \cdots & u_{m} & \cdots & u_{41}
\end{array}\right]^{T}
\end{aligned}
$$

where $\Delta_{n}$ is the deformation in spring $\mathrm{n}$ and $u_{m}$ is the nodal displacement according to the DOF $\mathrm{m}$. The compatibility matrix is sparse and thus only the nonzero elements are shown in Table $2-A_{i, j}$ is the deformation in spring $j$ caused by a unit displacement in DOF assigned to the row $i$ when all the other DOFs are null.

\begin{tabular}{|c|c|}
\hline value & element \\
\hline 1 & $\begin{array}{c}{[4,1] ;-[1,1] ;-[8,3] ;[18,4] ;-[9,5] ;-[19,6] ;[1,7] ;} \\
{[2,7] ;-[12,8] ;[13,10] ;-[3,11] ;[14,12] ;-[2,13] ;} \\
{[5,13] ;[24,14] ;[10,15] ;-[20,16] ;[11,17] ;} \\
{[21,18] ;-[4,19] ;-[5,19] ;[15,20] ;-[16,22] ;} \\
{[6,23] ;-[17,24] ;-[26,25] ;[34,26] ;-[27,27] ;} \\
{[22,28] ;[28,29] ;-[29,30] ;[30,31] ;-[35,32] ;} \\
{[31,33] ;-[23,34] ;-[32,35] ;[33,36] ;-[6,37] ;} \\
{[3,38] ;-[14,39] ;[17,39] ;[29,39] ;-[33,39] ;-} \\
{[22,40] ;-[23,40] ;-[24,41] ;-[25,41] ;-[34,41] ;} \\
{[35,41]}\end{array}$ \\
\hline 0.5 & $\begin{array}{c}{[12,2] ;-[13,2] ;[8,9] ;-[10,9] ;[27,9] ;-[31,9] ;} \\
{[12,14] ;-[15,14] ;[8,21] ;-[10,21] ;[27,21] ;-} \\
{[31,21]}\end{array}$ \\
\hline $\sin \alpha$ & {$[7,9] ;-[7,21]$} \\
\hline $\cos \alpha$ & $-[7,1] ;[7,13]$ \\
\hline$\frac{d_{b Y}}{\left(2 d_{b X}\right)}$ & {$[26,1] ;-[30,1]$} \\
\hline$\frac{1}{d_{b X}}$ & $\begin{array}{c}{[28,1] ;-[32,1] ;-[13,2] ;[16,2] ;-[18,2] ;[20,2] ;-} \\
{[28,13] ;[32,13] ;[13,14] ;-[16,14] ;-[18,14] ;-} \\
{[20,14]}\end{array}$ \\
\hline$\frac{1}{d_{c X}}$ & $-[9,9] ;[11,9] ;[9,21] ;-[11,21]$ \\
\hline$\frac{d_{b Y}}{d_{b X}}$ & {$[25,2]$} \\
\hline$\frac{\left(2 d_{b X}-d_{b Y}\right)}{\left(2 d_{b X}\right)}$ & {$[26,13] ;-[30,13]$} \\
\hline$\frac{\left(d_{b X}-d_{b Y}\right)}{d_{b X}}$ & {$[25,14]$} \\
\hline$\frac{d_{b X}}{2}$ & {$[4,37] ;-[5,37] ;-[1,38] ;[2,38]$} \\
\hline$\frac{d_{c X}}{2}$ & $-[12,39] ;[15,39]$ \\
\hline$\frac{d_{b Y}}{2}$ & $-[24,40] ;-[25,40]$ \\
\hline
\end{tabular}

Table 2

Nonzero elements of the compatibility matrix.

The extended stiffness matrix of the beam-to-column joint can be computed according to equation

$$
K=A^{T} \cdot k \cdot A
$$

where $k$ is a $35 \times 35$ diagonal matrix where $k_{i, i}=k_{i}$, and $i=1, \ldots, 35$ is the stiffness of spring $i$.

The stiffness matrix computed from (7) requires static condensation in order to become only explicit in terms of the external nodes displacements. Making 


$$
\begin{gathered}
u=\left[\begin{array}{l}
u_{\text {ext }} \\
u_{\text {int }}
\end{array}\right] \text { with } u_{\text {ext }}=\left[\begin{array}{c}
u_{1} \\
\vdots \\
u_{36}
\end{array}\right] \text { and } u_{\text {int }}=\left[\begin{array}{c}
u_{37} \\
\vdots \\
u_{41}
\end{array}\right] \\
F=\left[\begin{array}{c}
F_{\text {ext }} \\
F_{\text {int }}
\end{array}\right] \text { with } F_{\text {ext }}=\left[\begin{array}{c}
F_{1} \\
\vdots \\
F_{36}
\end{array}\right] \text { and } F_{\text {int }}=\left[\begin{array}{c}
0 \\
\vdots \\
0
\end{array}\right]
\end{gathered}
$$

yields

$$
F=K \cdot u \rightarrow\left[\begin{array}{c}
F_{\text {ext }} \\
F_{\text {int }}
\end{array}\right]=\left[\begin{array}{cc}
K_{\text {ext }} & K_{\text {ie }} \\
K_{\text {ie }} & K_{\text {int }}
\end{array}\right] \cdot\left[\begin{array}{l}
u_{\text {ext }} \\
u_{\text {int }}
\end{array}\right]
$$

so that the condensed stiffness matrix may be computed from

$$
K_{c}=K_{\text {ext }}-K_{\text {ie }}\left(K_{\text {int }}\right)^{-1} K_{\text {ie }}
$$

\subsection{Non-linear analysis procedure}

Due to the internal DOFs in the models represented in Fig. 8 to 13, if a nonlinear analysis is required, the proposed beam-column joint elements require a procedure to determine the internal nodal displacements that satisfy internal equilibrium of the element for each iteration of the global solution algorithm. The approach developed by Lowes and Altoontash [30] for reinforced concrete beam-column joints was followed in the implementation of the $3 \mathrm{D}$ joint macro element presented in the former section in OpenSees [7].

The solution for the internal nodal displacements, and thus the material state of the beam-to-column joint element, developed by Lowes and Altoontash [30] is a classical Newton-Raphson iteration scheme. According to this scheme, the internal node displacements $u_{\text {int, } t}$ at iteration $\mathrm{t}$ associated to the imposed external node displacements $u_{\text {ext, } t}$ are computed starting from the node internal displacements at iteration $t-1$ and the material responses of the components/connections according to the following procedure:

(i) computation of a first estimate of the deformations of the components/connections

$\Delta=A \cdot\left[\begin{array}{c}u_{\mathrm{ext}} \\ u_{\text {int }, t-1}\end{array}\right]$

where $u_{\text {ext }}$ stands for the vectors of displacements assigned to external nodes, $u_{\text {int }}$ stands for the vectors of displacements assigned to internal nodes, $\Delta$ stands for the vectors of deformations of the components/connections;

(ii) computation of the internal forces $\left(f_{i}\right)$ and the tangent stiffness $\left(k_{i}\right)$ of the components/connections for $\Delta$

(iii) computation of the unbalanced nodal forces in the internal nodes $\left(F_{\text {int }}\right)$

$F_{\text {int }}=\tilde{A}^{T} . f$

where $f$ stands for the vectors of internal forces in the components/connections, $F_{\text {int }}$ stands for the vectors of unbalanced forces in the internal nodes and $\tilde{A}$ stands for the last columns of the compatibility matrixes (related with the internal DOFs);

(iv) iterative internal cycles until the unbalanced forces are small enough (i-th cycle)

a. check for convergence

$F_{\text {int }}^{i}\left(F_{\text {int }}^{i}\right)^{T}<$ tolerance $\rightarrow$ convergence $\rightarrow$ STOP

b. computation of the internal node displacements making use of the Newton-Raphson iteration formula

$u_{i n t}^{i+1}=u_{i n t}^{i}-\left(\tilde{A}^{T} k \tilde{A}\right)^{-1} F_{i n t}^{i}$

where $k$ stands for diagonal matrix where $k_{j, j}=k_{j}$ for each component/connection.

c. computation of the deformations of the components/connections

$$
\Delta^{i+1}=A \cdot\left[\begin{array}{c}
u_{\text {ext }} \\
u_{\text {int }}^{i+1}
\end{array}\right]
$$

d. computation of the internal forces and the tangent stiffness of the components/connections for $\Delta^{i+1}$;

e. computation of the unbalanced nodal forces in the internal nodes

$F_{\text {int }}^{i+1}=\tilde{A}^{T} \cdot f$

f. new internal cycle $(i=i+1)$

\section{Application example}

The 3D frame represented in Fig. 16 to 18 was selected to illustrate the application of the 3D joint macro-element presented in section 4 . It consists of pinned column base joints and full-strength and rigid external beam-to-column joints (BCJ1/2/5/6) and deformable internal beam-to-column joints (BCJ2/3). The frame was analysed for the load cases LC_1 and LC_2 presented in Table 3 , with the load patterns $p_{1}$ to $p_{4}$ represented in Fig. 16 and 17, using OpenSees. The lumped plasticity element (beamWithHinges element from OpenSees) was used for simulating material non-linear behaviour in the columns and beams of the frame. An elastic-plastic behaviour for steel was considered with Young's modulus $E=210 G P a$, Poisson's ratio $v=0.3$, yield strength $f_{y}=275 \mathrm{MPa}$ and $0.25 \%$ linear strain hardening (as a percentage of the initial elastic modulus).

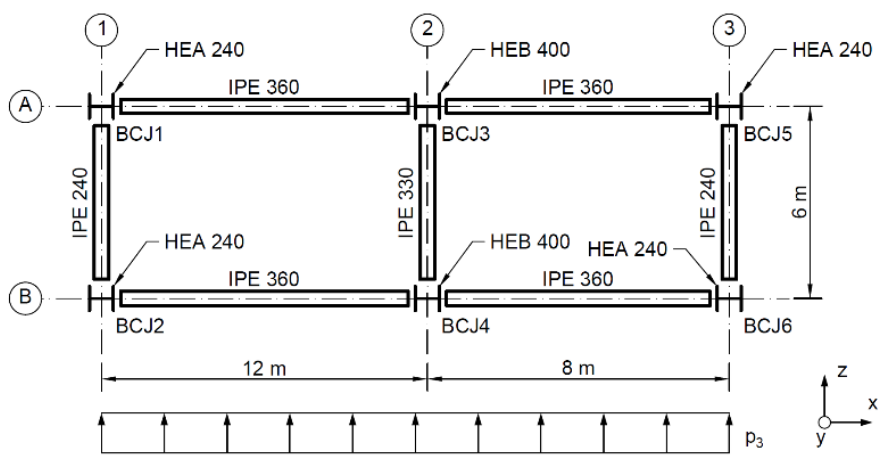

Fig. 16 Plan view of the 3D frame.

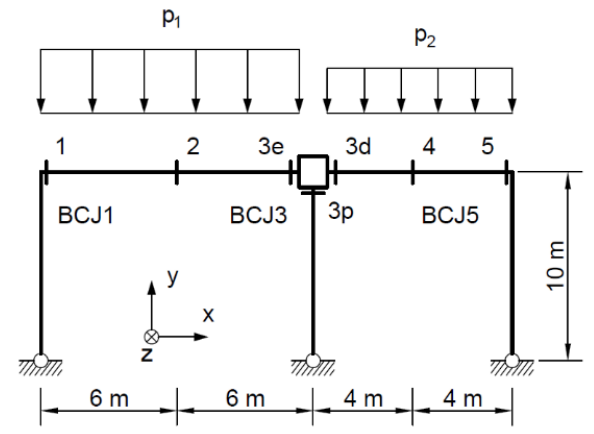

FRAME A

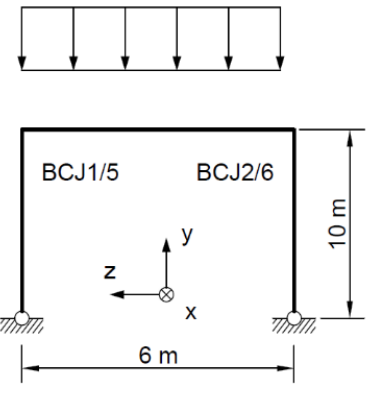

FRAME $1 / 3$

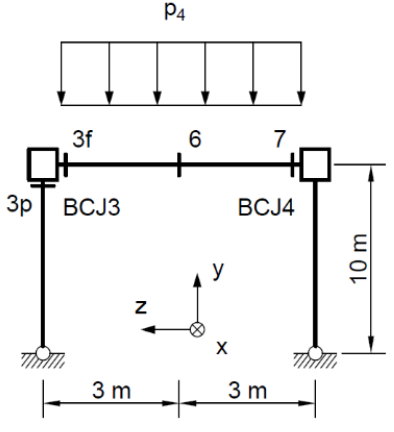

FRAME 2
Fig. 17 Schematic representation of the side view of the frames (Frame B is similar to Frame A but no reference cross-sections are considered in Frame B). 


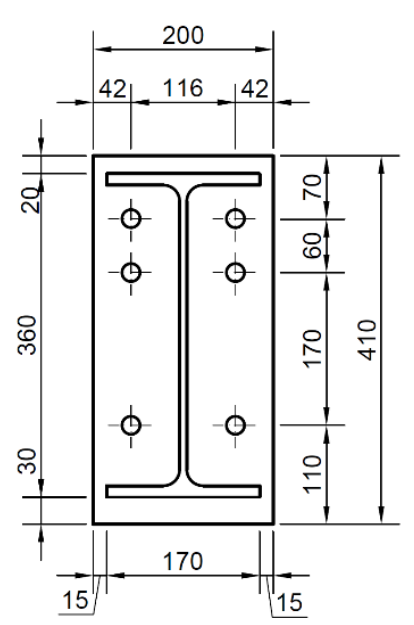

Major axis joints

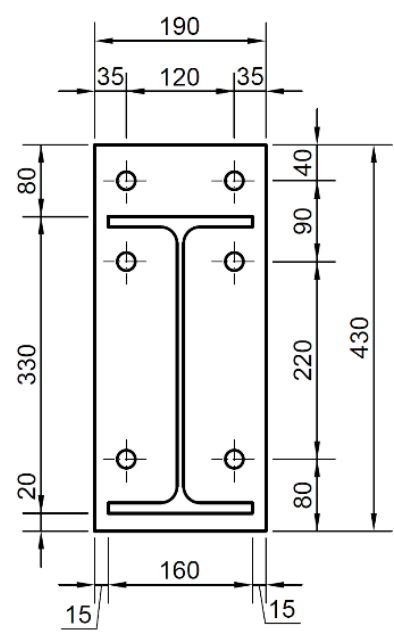

Minor axis joints

Fig. 18 Detailing of the end plates in major and minor axis joints of BCJ2/3 (in mm).

Table 3

Load cases.

\begin{tabular}{lcccc}
\hline \multirow{2}{*}{ load case } & \multicolumn{4}{c}{ load patterns } \\
\cline { 2 - 5 } & $p_{1}(\mathrm{kN} / \mathrm{m})$ & $p_{2}(\mathrm{kN} / \mathrm{m})$ & $p_{3}(\mathrm{kN} / \mathrm{m})$ & $p_{4}(\mathrm{kN} / \mathrm{m})$ \\
\hline LC_1 & 20 & 15 & 0.4 & 4 \\
LC_2 & 26 & 20 & 1.0 & 8 \\
\hline
\end{tabular}

Tables 4 and 5 present the mechanical properties of the components of the major and minor axis joints computed according to EC3-1-8 [10] - the component web panel in transverse tension/compression is assessed according to Neves, Silva and Vellasco [28] and Jaspart, Pietrapertosa, Weynand, Busse and Klinkhammer [29]. The resulting mechanical properties of the 0D elements of the $3 \mathrm{D}$ joint macro-element are summarized in Table 6 .

Table 4

Stiffness coefficients and resistance of the major axis joint components.

\begin{tabular}{lrr}
\hline component & $\begin{array}{r}\text { stiffness coefficient } \\
(\mathrm{mm})\end{array}$ & $\begin{array}{r}\text { resistance } \\
(\mathrm{kN})\end{array}$ \\
\hline column web panel in shear & 10.89 & 999.9 \\
column web in compression & 10.21 & 934.6 \\
column web in tension, row 1 & 3.171 & 639.4 \\
column web in tension, row 2 & 3.647 & 767.8 \\
column web in tension, row 3 & 3.808 & 767.8 \\
column flange in bending, row 1 & 50.23 & 507.1 \\
column flange in bending, row 2 & 57.76 & 508.3 \\
column flange in bending, row 3 & 92.00 & 508.3 \\
end-plate in bending, row 1 & 11.99 & 410.6 \\
end-plate in bending, row 2 & 7.049 & 385.9 \\
end-plate in bending, row 3 & 13.59 & 393.2 \\
bolts in tension, row 1 & 8.525 & 508.4 \\
bolts in tension, row 2 & 8.525 & 508.4 \\
bolts in tension, row 3 & 8.525 & 508.4 \\
\hline
\end{tabular}

Table 5

Stiffness coefficients and resistance of the minor axis joint components.

\begin{tabular}{lrr}
\hline component & $\begin{array}{r}\text { stiffness coefficient } \\
(\mathrm{mm})\end{array}$ & $\begin{array}{r}\text { resistance } \\
(\mathrm{kN})\end{array}$ \\
\hline beam flange in compression & $\infty$ & 896.5 \\
bolts in tension & 29.1 & 508.4 \\
end-plate in bending, row 1 & 18.2 & 386.9 \\
end-plate in bending, row 2 & 17.1 & 451.8 \\
end-plate in bending, row 3 & $\infty$ & 737.9 \\
beam web in tension, row 2 & $\infty$ & 625.4 \\
beam web in tension, row 3 & 1.2 & 115.7 \\
column web in transverse tension & 2.1 & 134.4 \\
column web in transverse compres- & & \\
sion & $\infty$ & 262.7 \\
column web in transverse tension: & & \\
punching shear & $\infty$ & 970.6 \\
column web in transverse compres- & & \\
sion: punching shear & & \\
\hline
\end{tabular}

Table 6

Mechanical properties of the springs.

\begin{tabular}{|c|c|c|c|c|}
\hline \multicolumn{2}{|c|}{ OD element } & $\begin{array}{r}\text { resistance } \\
(\mathrm{kN}, \mathrm{kNm})\end{array}$ & $\begin{array}{r}\text { initial } \\
\text { stiffness } \\
(\mathrm{kN} / \mathrm{m} \text {, } \\
\mathrm{kNm} / \mathrm{rad})\end{array}$ & $\begin{array}{r}\text { post-elastic } \\
\text { stiffness } \\
(\mathrm{kN} / \mathrm{m} \text {, } \\
\mathrm{kNm} / \mathrm{rad}\end{array}$ \\
\hline 07 (TD) & $\begin{array}{l}\text { column web panel } \\
\text { in shear }\end{array}$ & 1345.2 & 4139289 & 190407 \\
\hline $\begin{array}{l}01(\mathrm{TX}) \\
04(\mathrm{TX})\end{array}$ & $\begin{array}{l}\text { column web in } \\
\text { compression }\end{array}$ & 934.6 & 2144100 & 49314 \\
\hline $\begin{array}{l}02(\mathrm{TX}) \\
05(\mathrm{TX})\end{array}$ & $\begin{array}{l}\text { column web in } \\
\text { tension }\end{array}$ & 2175 & 1834394 & 18344 \\
\hline $\begin{array}{l}03 \text { (RZ) } \\
06 \text { (RZ) }\end{array}$ & $\begin{array}{l}\text { tions } \\
\text { (without column } \\
\text { web components) }\end{array}$ & 200.2 & 134462 & 2689 \\
\hline 08 (TY) & $\begin{array}{l}\text { column axial stiff- } \\
\text { ness }\end{array}$ & 7021 & 23076666 & 461533 \\
\hline 09(RZ) & $\begin{array}{l}\text { column bending } \\
\text { stiffness }\end{array}$ & 1147 & 672933 & 13458 \\
\hline $24(\mathrm{TZ})$ & top transverse & 115.7 & 252943 & 5058 \\
\hline $\begin{array}{l}25(\mathrm{TZ}) \\
22(\mathrm{RX})\end{array}$ & $\begin{array}{l}\text { bottom transverse } \\
\text { external connec- }\end{array}$ & 134.4 & 435648 & 8712 \\
\hline $23(\mathrm{RX})$ & $\begin{array}{l}\text { tions } \\
\text { (without column } \\
\text { web components) }\end{array}$ & 123.5 & 165127 & 3302 \\
\hline
\end{tabular}

Two analysis were performed for each load case to assess the influence of a rigorous modelling of the behaviour of beam-to-column joints: (i) threedimensional analysis considering rigid and full strength beam-to-column joints (case RIG) and (ii) three-dimensional analysis considering the 3D joint macroelement in the internal beam-to-column joints (case 3DJ).

The values of the bending moment for ten reference cross-sections (see Fig. 17) for LC_1 and LC_2 are listed in Tables 7 and 8, respectively. These tables clearly show that the the models with rigid joints (RIG) present significant errors in the bending moment distribution when compared to the component models that account for the deformability of the joints (3DJ).

Table 7

Bending moments for LC_1.

\begin{tabular}{lrrrrrrr}
\hline \multirow{2}{*}{ cross- } & \multicolumn{9}{c}{ RIG } & & \multicolumn{2}{c}{$3 \mathrm{DJ}$} \\
\cline { 2 - 4 } \cline { 7 - 8 } section & \multicolumn{1}{c}{$\begin{array}{c}\text { My } \\
(\mathrm{kNm})\end{array}$} & $\begin{array}{c}\text { error } \\
(\%)\end{array}$ & $\begin{array}{c}\mathrm{Mz} \\
(\mathrm{kNm})\end{array}$ & $\begin{array}{c}\text { error } \\
(\%)\end{array}$ & & $\begin{array}{c}\text { My } \\
(\mathrm{kNm})\end{array}$ & $\begin{array}{c}\mathrm{Mz} \\
(\mathrm{kNm})\end{array}$ \\
\hline 1 & 1.2 & 54.1 & 90.2 & 3.3 & & 2.5 & 93.3 \\
2 & 3.1 & 10.2 & 179.2 & 8.5 & & 3.4 & 195.9 \\
$3 \mathrm{e}$ & 6.5 & 44.5 & 244.8 & 17.2 & & 4.5 & 208.9 \\
$3 \mathrm{~d}$ & 3.8 & 135.2 & 169.9 & 22.0 & & 1.6 & 139.2 \\
$3 \mathrm{p}$ & 41.7 & 6.4 & 83.5 & 6.1 & & 39.1 & 78.7 \\
$3 \mathrm{f}$ & 2.9 & 4.9 & 42.4 & 6.5 & & 3.0 & 39.8 \\
4 & 0.8 & 37.1 & 28.0 & 29.7 & & 1.3 & 39.9 \\
5 & 0.6 & 69.3 & 2.3 & 59.2 & & 1.8 & 5.6 \\
6 & 0.0 & 99.8 & 12.6 & 27.3 & & 0.0 & 17.3 \\
7 & 2.9 & 5.1 & 53.3 & 29.1 & & 3.0 & 41.3 \\
\hline
\end{tabular}

Table 8

Bending moments for $\mathrm{LC} \_2$.

\begin{tabular}{lrrrrrrr}
\hline \multirow{2}{*}{$\begin{array}{c}\text { cross- } \\
\text { section }\end{array}$} & \multicolumn{9}{c}{$\begin{array}{c}\text { My } \\
(\mathrm{kNm})\end{array}$} & $\begin{array}{c}\text { error } \\
(\%)\end{array}$ & $\begin{array}{c}\mathrm{Mz} \\
(\mathrm{kNm})\end{array}$ & $\begin{array}{c}\text { error } \\
(\%)\end{array}$ & & \multicolumn{2}{c}{$\begin{array}{c}\text { My } \\
(\mathrm{kNm})\end{array}$} & $\begin{array}{c}\mathrm{Mz} \\
(\mathrm{kNm})\end{array}$ \\
\hline 1 & 9.0 & 53.6 & 144.6 & 1.8 & & 19.4 & 147.3 \\
2 & 8.5 & 60.3 & 251.3 & 2.4 & & 5.3 & 257.6 \\
$3^{\mathrm{e}}$ & 8.7 & 75.7 & 255.6 & 6.1 & & 5.0 & 240.9 \\
$3^{\mathrm{d}}$ & 7.0 & 19.0 & 139.7 & 7.1 & & 8.7 & 150.4 \\
$3^{\mathrm{p}}$ & 125.0 & 113.7 & 91.2 & 28.8 & & 58.5 & 128.1 \\
$3^{\mathrm{f}}$ & 2.0 & 76.9 & 94.7 & 66.1 & & 8.7 & 57.0 \\
4 & 3.2 & 48.3 & 65.3 & 1.3 & & 6.1 & 64.4 \\
5 & 1.7 & 86.3 & 31.1 & 44.6 & & 12.1 & 21.5 \\
6 & 2.0 & 85.8 & 94.7 & 65.4 & & 13.9 & 57.2 \\
7 & 2.3 & 83.7 & 116.4 & 96.8 & & 14.1 & 59.1 \\
\hline
\end{tabular}

This example shows that the $3 \mathrm{D}$ macro-element is able to capture the influence of the deformability of the beam-to-column joints in an internal node of a 3D steel frame. It also highlights that with the availability of macroelements to simulate the nodal regions of a 3D frames in computer software, it is possible to carry out efficiently the global analysis of a 3D steel frame with proper accounting for the influence of the deformability of the joints. 


\section{Concluding remarks}

This paper presented a methodology for the analysis of steel structures using 3D structural models and incorporating the behaviour of the steel joints using $3 \mathrm{D}$ component models.

It is shown that the practical way to achieve this goal is the implementation of a node macro-element that encapsulates the deformability of the joints connected to a column. This strategy was implemented in the open source software OpenSeeS and may be easily implemented in commercial software.

\section{Acknowledgments}

The research leading to these results has received funding from FEDER funds through the Competitivity Factors Operational Programme - COMPETE and by national funds through FCT - Foundation for Science and Technology within the scope of the project POCI-01-0145-FEDER-007633 and through the Regional Operational Programme CENTRO2020 within the scope of the project CENTRO-01-0145-FEDER-000006.

\section{References}

[1] Jaspart, J.-P. and K. Weynand, Design of joints in steel and composite structures. ECCS Eurocode Design Manuals. 2016: ECCS - European Convention for Constructional Steelwork.

[2] Davies, J.M. and K. Morita. Three dimensional cross joints under combined axial branch loading. in Tubular Structures IV. 2001. Delft.

[3] Harada, Y. and L.S.d. Silva. Approach to macro-modeling of 3D tubular column-to-beam joint: an extension of component method for joint modeling. in Connections in Steel Structures VIII. 2016. Boston.

[4] Cabrero, J.M. and E. Bayo, The semi-rigid behaviour of three-dimensional steel beam-tocolumn joints subjected to proportional loading. Part I. Experimental evaluation. Journal of Constructional Steel Research, 2007. 63: p. 1241-1253.

[5] Gervásio, H., S. Dimova, and A. Pinto, Benchmarking the life-cycle environmental performance of buildings. Sustainability 2018. 10(5).

[6] Silva, L.S.d., R. Simões, and H. Gervásio, Design of steel structures. Eurocode 3: Design of steel structures. parte 1-1: general rules and rules for buildings. ECCS Eurocode Design Manuals. 2013. 456

[7] McKenna, F., et al., Open System for Earthquake Engineering Simulation (OpenSees). Pacific Earthquake Engineering Research Center, University of California. 2000: Berkeley.

[8] Landolfo, R., et al., Design of steel structures for buildings in seimic areas. Eurocode 8: Design of structures for earthquake resistance. Part 1: general rules, seismic action and rules for buildings, ed. E.E.D. Manuals. 2017: Wiley.

[9] Simões da Silva, L., R. Simões, and H. Gervásio, Deep Underground Neutrino Experiment (DUNE). 2018, University of Coimbra.

[10] CEN, EN 1993-1-8, Eurocode 3: Design of steel structures, Part 1-8: Design of joints, European Committee for Standardisation, Editor. 2005: Brussels. p. 133.

[11] Feldmann + Weynand GmbH, COP - The connection Program. 2018: Aachen.

[12] Borges, L., NASCON - Steel connection analyser 2012: Coimbra.

[13] ISISE, Steel Connections Calculator ECCS EC3 1.8 (iOS and Android). 2018: Coimbra.

[14] Autodesk Inc., Robot Strucctural Analysis Professional. 2012: Providence.

[15] Tschemmernegg, F., D. Rubin, and A. Pavlov. Application of the component method to composite joints. in Control of the semi-rigid behaviour of civil engineering structural connections. 1998. Liège: European Commission.

[16] Huber, G. and F. Tschemmernegg, Modelling of beam-to-column joints: test evaluation and practical application. Journal of Constructional Steel Research, 1998. 45(2): p. 199-216.

[17] Castro, J.M., A.Y. Elghazouli, and B.A. Izzuddin, Modelling of the panel zone in steel and composite moment frames. Engineering Structures, 2005. 27: p. 129-144.

[18] Alves, S.F.S.J., Comportamento de juntas soldadas em nó interno com vigas de diferentes alturas e aço de alta resistência, in Departamento de Engenharia Civil. 2008, Universidade de Coimbra: Coimbra. p. 373.

[19] Costa, R., F. Gentili, and L. Simões da Silva. Development of a three dimensional model for beam-to-column joints under static loading. in X Congresso de Construção Metálica e Mista. 2015. Coimbra.

[20] Augusto, H., et al., Characterization of web panel components in double-extended bolted endplate steel joints. Journal of Constructional Steel Research, 2016. 116: p. 271-293.

[21] Augusto, H., et al., Cyclic behaviour characterization of web panel components in bolted endplate steel joints. Journal of Constructional Steel Research, 2016. 133: p. 310-333.

[22] Denis, F., 3DJOINTS - 3D behaviour of steel joints (in Portuguese). 2016, University of Coimbra.

[23] Valdez, J., Numerical and experimental characterization of the interation between major and minor axis joints. 2017, University of Coimbra

[24] Costa, R., et al., Experimental behaviour of 3D end-plate beam-to-column bolted steel joints. Engineering Structures, 2019. 188: p. 277-289.

[25] Silva, L.S.d., Towards a consistent design approach for steel joints under generalized loading. Journal of Constructional Steel Research, 2008. 64: p. 1059-1075.

[26] Gentili, F., R. Costa, and L. Simões da Silva. Definition and implementation of a simplified model for steel connections in an open source software. in Eighth International Conference on Advances in Steel Structures. 2015. Lisbon.

[27] Costa, R., F. Gentili, and L. Simões da Silva. Simplified model for connections of steel structures in OpenSees. in Nordic Steel Construction Conference. 2015. Tampere.

[28] Neves, L., L.S.d. Silva, and P. Vellasco. A model for predictng the stiffness of beam to concrete filled column and minor axis joints under static monotonic loading. in Eurosteel 2005 - 4th European conference on steel and composite structures - research - Eurocodes practice. 2005. Aachen.

[29] Jaspart, J.P., et al., Development of a full consistent design approach for bolted and welded joints in buildings frames and trusses between steel members made of hollow and/or open sections. 2005, CIDECT Report 5BP-4/05.

[30] Lowes, L.N. and A. Altoontash, Modeling reinforced-concrete beam-column joints subjected to cyclic loading. Journal of Structural Engineering-ASCE, 2003. 129(12): p. 1686-1697. 